\title{
Boundary and Object Detection in Real World Images
}

\author{
YORAM YAKIMOVSKY \\ Jet Propulsıon Laboratory, Pasadena, Calıfornia
}

ABSTRACT A computer solution to the problem of automatic location of objects in digital pictures is presented A self-scalıng local edge detector that can be applied in parallel on a picture is described Clustering algorithms and sequential boundary following algorithms process the edge data to local images of objects and generate a data structure that represents the imaged objects

KEY WORDS AND PHRASEs scene analysis, image processing, clustering, statistical decision analysis, maximum likelıhood test

CR CATEGORIES $\quad 363,383$

\section{Introduction}

A substantial amount of research has been done in developing techniques for locating objects of interest automatically in digitized pictures Drawing the boundaries around objects is essential for pattern recognition, object tracking, image enhancement, data reduction, and various other applications. References [18-20] constitute a good survey of research and applications in image processing and picture analysis.

Most researchers of picture analysis have assumed that (1) the image of an object is more or less uniform or smooth in its local properties (that is, illumination, color, and local texture are smoothly changing inside the image of an object); and (2) there is detectable discontinuity in local properties between images of two different objects. We will adopt these two assumptions in this paper and assume no textural image (see [1] for an example of texture image analysis that does not make these assumptions).

The work on automatic location of objects in digitızed ımages has split into two approaches: edge detection and edge following versus region growing. Edge detection applies local independent operators over the picture to detect edges and then uses algorithms to trace the boundaries by following the local edge detected A recent survey of literature in this area is given in [7]. The region growing approach uses various clusterıng algorıthms to grow regıons of almost uniform local properties in the image (see $[5,2,11,24]$ for typical applications) More detaled references will be given later

In this paper the two approaches are combined to complement each other; the result is a more powerful mechanism to segment pictures into objects. We developed a new edge detector and combined it with new region growing techniques to locate objects; in so doing we resolved the confusion in regular edge following that results where more than one isolated object on a uniform background is in the scene (see [17]).

This report describes the following contributions: (1) a new and "optımal" (given certain assumptions) edge detector; (2) a simple one-pass region growing algorithm that

Copyright $(\mathcal{O}$ 1976, Association for Computing Machinery, Inc General permission to republish, but not for profit, all or part of this material is granted provided that ACM's copyright notice is given and that reference is made to the publication, to its date of issue, and to the fact that reprinting privileges were granted by permission of the Association for Computing Machinery

This paper presents the results of one phase of research carried out at the Jet Propulsion Laboratory, Calıfornia Institute of Technology, under Contract NAS7-100, sponsored by the National Aeronautics and Space Administration

Author's present address Ph D-M D Program, Unıversity of Miamı School of Medicine, Miamı, FL 33152 
is implemented on a minicomputer, utilizing the edge detector output; (3) the application of path generator algorithms and "shortest path" algorithms for boundary following to close open-edge lines into boundaries around regions; (4) special purpose region growing intended to close open edges (cracks); and (5) a special clustering algorithm that simplifies the region structure resulting from the application of (1) through (4)

\section{Definition of Terms}

The input is expected to be in the matrix form $\mathbf{V}(i, j), i=1, \ldots, N, j=1, \ldots, M$, where $\mathrm{V}$ is a vector in $R^{n}$ and $n$ is a function of the sensory system, usually 1 (gray level picture), 3 (color or $x, y, z$ coordinates of the surface in the scanning direction), or 6 (color and 3-D information). An edge unit separates two adjacent matrix points; that is, an edge unit is between $(i, j)$ and $(i+1, j)$ or between $(i, j)$ and $(i, j+1)$ for some $i, j$ (see Figure 1).

An edge unit is usually adjacent on both ends to other edge units. There are 64 combinations of edge units continuing an edge unit, since each of the edge units $e_{1}, e_{2}, e_{3}$, $e_{1}^{1}, e_{2}^{1}, e_{3}^{1}$ in Figure 1 may or may not exist.

Two points on the grid $(I, J)$ and $(K, L)$ are said to be in the same region if there is a path sequence $\left(i_{1}, j_{1}\right), \ldots,\left(i_{n}, j_{n}\right)$ such that $i_{1}=I, j_{1}=J, i_{n}=K$, and $j_{n}=L$, where $\left(i_{m}, j_{m}\right)$ is adjacent to $\left(i_{m+1}, j_{m+1}\right)$ for $m=1, \ldots, n-1$ and there is no edge unit between the two. A region will be a maximum set of points satisfying that property.

An edge line (or an edge) between region $R_{1}$ and region $R_{2}$ is the maximal sequence of adjacent edge units such that each edge unit in the sequence is between two matrix points, one belonging to $R_{1}$ and the other belonging to $R_{2}$ It is possible that an edge line is inside a region $\left(R_{1}=R_{2}\right)$.

An edge line that is between two different regions is called a boundary. An edge line that is inside a region is called a crack. An open crack is a crack in which at least one end terminates without connecting to any edge line. A closed crack is one in which each end terminates on another edge line For instance cracks appear when an object is smoothly disappearıng into the background on one side and has detectable discontınuity on the other side, as shown in Figure 2.

Usıng the above definitions, this report first presents an edge detector that detects edge units in parallel locally on the whole image. Then a regıon grower that groups matrix points into regions and edge units into boundaries and cracks is presented. A local region grower that tries to break a region with a crack in it into two regions for which the crack is part of the common boundary is presented next Alternatively, an open crack extending algorithm is suggested to connect the open edge unit of the crack to another edge line.

\section{The Local Edge Detector}

The edge operator is a detector of local discontinuity in an image When applied between two adjacent points such as $(i, j)$ and $(i+1, j)$, it should return a value that will measure the confidence that there is an edge between $(i, j)$ and $(i+1, j)$. Since we work with noisy input to achieve reliability, the operator must look at two 2-dimensional (2-D) neighborhoods $N_{1}$ and $N_{2}$ to obtain a reliable value Neighborhood $N_{1}$ includes $(i, j)$ and a few adjacent points; $N_{2}$ includes $(i+1, j)$ and a few adjacent points; and $N_{1} \cap N_{2}=0$. As a

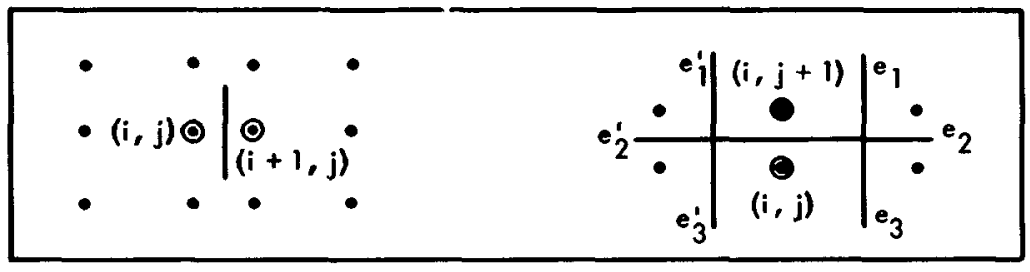

FIG 1 Edge unit structure 
result the value returned will measure the confidence that the neighborhoods belong to images of different objects

Edge detection is actually composed of three components: (1) measuring differences between image structures in the two neighborhoods, (2) selecting the proper neighborhoods; and (3) lockıng on the exact position of the edge. Discussion of each of these steps follows.

\section{Measuring Differences in Structure Between Two Neighborhoods}

Any techniques that measure structural differences must make some assumptions (explicitly or implicitly) concerning the structure of an edge and the area inside a region. Binford and Hershkovitz [4] suggest three possible ideal edges defined by the intensity profile on a normal-to-the-edge line (Figure 3).

All of these 1dealized edges are in reality washed with Gaussian noise on both sides, where the noise is both hardware noise and the result of surface irregularities. Basically, the decision is between two hypotheses:

$H_{0}$ : the readings in $N_{1}$ and $N_{2}$ are taken from the same object;

$H_{1}$ : the readings in $N_{1}$ and $N_{2}$ are taken from different objects

Neighborhoods $N_{1}$ and $N_{2}$ are the neighborhoods mentioned in Section 3 , and the decision as to how to choose them will be described in Section 5.

An optımal (best for its size) decision between $H_{0}$ and $H_{1}$ will utilıze the maxımum
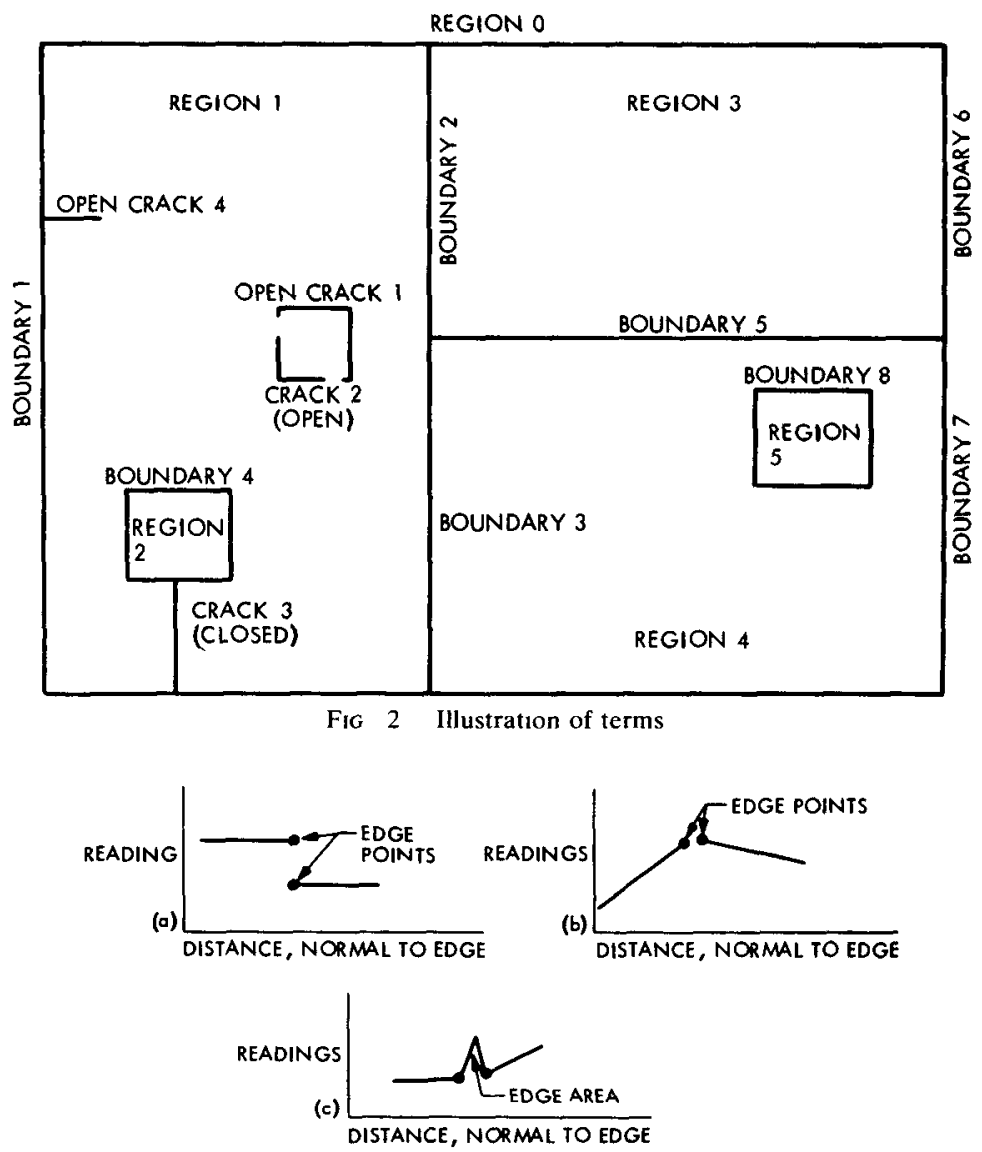

Fig 3 Typical edges (a) idealized step edge (domınant edge type in visual images), (b) pure gradient edge (corners are especially frequent in analysis of 3-D images when direct measure of distance is avallable), (c) spike edge (appears frequently in corner edges in visual images) 
likelihood ratio as follows: Let $\boldsymbol{P}_{0}$ be the maximum likelihood estimate of the structure (reading in $N_{1}$ and $N_{2}$ ), given that $H_{0}$ is true, and let $P_{1}$ be the maximum likelihood estimate of the structure, assuming that $H_{1}$ is true. Then choose $H_{1}$ when $P_{1} / P_{0}>$ $K$, choose $H_{0}$ when $P_{1} / P_{0}<K$, and choose at random when $P_{1} / P_{0}=K$.

This decision will be optimal for a given allowed probability of false negative (see the Neyman-Pearson Test $[8$, p. 55]); hence if the structure assumptions are valid we have an ideal edge detector, given only readings in $N_{1}$ and $N_{2}$. (We deal with Gaussian probabilities; hence we ignore $P_{1} / P_{0}=K$.) The conclusion is that $P_{1} / P_{0}$ is the best measure of the edge strength. Following are two examples of applying these principles to the edges of types (a) and (b) in Figure 3.

Example 1 Assume that the edges and surfaces will be of type (a) as in Figure 3 with added white noise which is object-dependent. Then $\boldsymbol{H}_{0}$ and $\boldsymbol{H}_{1}$ become

$\boldsymbol{H}_{0}$ : the readings in both $N_{1}$ and $N_{2}$ are independently taken from the same normal distribution $N\left(\mu_{0}, \sigma_{0}\right)$ with unknown $\mu_{0}, \sigma_{0}$;

$H_{1}$ : the readings on $N_{1}$ are independently taken from normal distribution $N\left(\mu_{1}, \sigma_{1}\right)$, the readings on $N_{2}$ are taken from normal distribution $N\left(\mu_{2}, \sigma_{2}\right)$, and $\left(\mu_{1}, \sigma_{1}\right)$ need not be equal to $\left(\mu_{2}, \sigma_{2}\right)$.

To apply the maximum likelihood ratıo principle we must find a maxımum likelihood estimate for $\left(\mu_{0}, \sigma_{0}\right),\left(\mu_{1}, \sigma_{1}\right)$, and $\left(\mu_{2}, \sigma_{2}\right)$ Given $\left(x_{1}, \ldots, x_{n}\right)$ readings taken from a normal distribution with unknown $(\mu, \sigma)$, the maximum likelihood estimates for $(\mu, \sigma)$ are $(\bar{\mu}, \bar{\sigma})$. When

$$
\bar{\mu}=\frac{1}{n} \sum_{i=1}^{n} x_{1} \quad \text { and } \quad \bar{\sigma}^{2}=\frac{1}{n} \sum_{l=1}^{n}\left(x_{i}-\mu\right)^{2},
$$

the probability density that a reading $x_{\imath}$ is generated by $N(\bar{\mu}, \bar{\sigma})$ is

$$
(1 / \sqrt{ }(2 \pi) \sigma) \cdot e^{-\left(x_{i}-\bar{\mu}\right)^{2} / 2 \bar{\sigma}^{2}}
$$

Assuming that $\left(x_{1}, \ldots, x_{n}\right)$ are independently taken from normal distribution $N(\bar{\mu}, \tilde{\sigma})$, then the joint probability density of generating the combined reading is the product of the individual terms.

$$
\begin{aligned}
& P_{\max }=P_{(\bar{\mu}, \bar{\sigma})}\left(x_{1}, \ldots, x_{n}\right)
\end{aligned}
$$

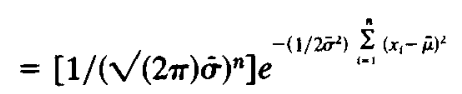

$$
\begin{aligned}
& =\left[1 / \sqrt{ }(2 \pi) \cdot \sigma^{n}\right] e^{-n \sigma^{2} / 2 \sigma^{2}} \\
& =\left(1 / 2 \pi^{n}\right) \cdot e^{n / 2} \cdot\left(1 / \sigma^{n}\right) .
\end{aligned}
$$

Hence if the readings on $N_{1}$ are $\left(x_{1}, \ldots, x_{m}\right)$ and on $N_{2}\left(y_{1}, \ldots, y_{n}\right)$, then on $N_{1}$,

$$
\mu_{1}=\frac{1}{m} \sum_{i=1}^{m} x_{i}, \quad \sigma_{1}^{2}=\frac{1}{m} \sum_{i=1}^{m}\left(x_{i}-\mu_{1}\right)^{2}, \quad P_{1}=\left(1 /(2 \pi)^{m / 2}\right) \cdot e^{-m / 2} \cdot 1 / \sigma_{1}^{m}
$$

on $N_{2}$,

$$
\mu_{2}=\frac{1}{m} \sum_{i=1}^{n} y_{i}, \quad \sigma_{2}^{2}=\frac{1}{n} \sum_{i=1}^{n}\left(y_{1}-\mu_{2}\right)^{2}, \quad P_{2}=\left(1 /(2 \pi)^{n / 2}\right) \cdot e^{-n / 2} \cdot 1 / \sigma_{2}^{n} ;
$$

and on $N_{1}$ combined with $N_{2}$,

$$
\begin{aligned}
& \mu_{0}=\left(m \mu_{1}+n \mu_{2} /(m+n),\right. \\
& \sigma_{0}^{2}=\left[m \sigma_{1}^{2}+n \cdot \sigma_{2}^{2}+m\left(\mu_{0}-\mu_{1}\right)^{2}+n\left(\mu_{0}-\mu_{2}\right)^{2}\right] /(m+n), \\
& P_{0}=\frac{1}{(2 \pi)^{(m+n) / 2}} \cdot e^{(-m+n) / 2} \cdot 1 / \sigma_{0}^{m+n} .
\end{aligned}
$$


Where $H_{1}$ holds we further assume that the readings on the two neighborhoods are independent; this results in the joint probability density of $P_{1}$ and $P_{2}$ being the product of $P_{1} \cdot P_{2}$ Hence the maximum likelıhood ratio is $P_{1} \cdot P_{2} / P_{0}$. Squaring this expression, which saves computations of square roots, results in the following expression for the edge value:

$$
P_{1}^{2} \cdot P_{2}^{2} / P_{0}^{2}=\left(\sigma_{0}^{2}\right)^{m+n} /\left(\sigma_{1}^{2}\right)^{m} \cdot\left(\sigma_{2}^{2}\right)^{n}
$$

Note that the edge value suggested is self-scalıng with respect to noise and texture: In areas where $\sigma_{1} \cong \sigma_{2} \cong \sigma_{0} \gg 0$ (highly textured areas or the result of noisy hardware) the edge value will be low, near 1 , while any small steps in almost uniform areas will be recognized early. In practice, we computed the variance of noise in the hardware by sampling over time the same points in static scenes The computed variance is taken always to be at least the hardware noise. Thus divisions by zero in pathological cases were prevented.

At this point it may be worthwhile to compare our approach with that of [9]. Both try to use a maxımum lıkelihood ratıo to compute scores for an edge. But while we have a simple model and a practical way of computing the confidence, [9] assumes a priori deterministic classification of all possible idealızed noise free structures into edges and no edges Then, for a given reading structure the noise assumption is used to compute the probability of all idealized structures that could have caused the readings These probabilities are used to decide whether or not the readings represent an edge.

It should be mentioned that other statistical techniques, e.g. $[4,22]$, were used for edge detection, but none of the edge detectors that appeared in the literature used the maxımum lıkelıhood test for edge value

Example 2 Here we assume that each matrix point $\mathbf{V}(i, j)$ is a 3-D vector $(x, y, z)$. Actually the raw readings are just distance $R(i, j)$, but to avoid a strong dependency on the sensor position. $R(i, j)$ is transformed into $(x, y, z)$. This is the form of input read from such a device as radar, which measures distances to surfaces, or from devices that measure the time of flight of light (laser) beams to an object. The $i, j$ corresponds to vertical and horizontal steps in the scanning angle. In that model two adjacent neighborhoods on the matrix $N_{1}$ and $N_{2}$ have readings $\left(x_{1}, y_{1}, z_{1}\right), \ldots,\left(x_{n}, y_{n}, z_{n}\right)$ in $N_{1}$ and $\left(x_{1}^{1}, y_{1}^{1}, z_{1}^{1}\right), \ldots,\left(x_{m}^{1}, y_{m}^{1}, z_{m}^{1}\right)$ in $N_{2}$. We assume that objects are almost planar locally with added white noise with mean 0 to position readings That is, if we read $\left(x_{1}, y_{1}, z_{1}\right)$, $\ldots,\left(x_{n}, y_{n}, z_{n}\right)$ in a small neighborhood on an object we have $a, b, c, d, \sigma$ such that $a^{2}+$ $b^{2}+c^{2}=1$ and $a x_{1}+b y_{2}+c z_{1}+d+N(0, \sigma)=0, \quad i=1, \ldots, n$.

With this assumption the edge detection decision will be a choice between $H_{0}$ and $H_{1}$ :

$H_{0}$. The readings in the two neighborhoods are taken from the same plane. That is, the readings on both $N_{1}$ and $N_{2}$ satisfy for some $\left(a_{0}, b_{0}, c_{0}, d_{0}, \sigma_{0}\right)$ the equation $a_{0} x+b_{0} y+$ $c_{0} z+d_{0}+N\left(0, \sigma_{0}\right)=0$, where $a_{0}^{2}+b_{0}^{2}+c_{0}^{2}=1$ for all $(x, y, z)$ readings in $N_{1}$ and $N_{2}$.

$H_{1}$ : There are two not necessarily equal planar fits for the readings on $N_{1}$ and on $N_{2}$. That is, there are $\left(a_{1}, b_{1}, c_{1}, d_{1}, \sigma_{1}\right)$ for $N_{1}$ and $\left(a_{2}, b_{2}, c_{2}, d_{2}, \sigma_{2}\right)$ for $N_{2}$ such that $a_{1}^{2}+b_{1}^{2}+$ $c_{2}^{1}=1 ; a_{2}^{2}+b_{2}^{2}+c_{2}^{2}=1 ; a_{1} x_{2}+b_{1} y_{2}+c_{1} z_{2}+d_{1}+N\left(0, \sigma_{1}\right)=0, i=1, \ldots, n ; a_{2} x_{2}^{1}$ $=b_{2} y_{\imath}^{1}+c_{2} z_{\imath}^{1}+d_{2}+N\left(0, \sigma_{2}\right)=0, l=1, \ldots, m$

To apply the Neyman-Pearson principle for this case we want to find maxımum likelihood estimates. Maxımum likelihood estimates $a_{1}, b_{1}, c_{1}, d_{1}$ will be

$$
\begin{aligned}
V_{1} & =\sum_{\imath=1}^{n}\left(a_{1} x_{\imath}+b_{1} y_{\imath}+c_{1} z_{\imath}+d_{1}\right)^{2} \\
& =\min _{\substack{a, b, c, d \\
a^{2}+b^{2}+c^{2}=1}} \sum_{i=1}^{n}\left(a x_{\imath}+b y_{\imath}+c z_{\imath}+d\right)^{2} \text { and } \sigma^{2}=V_{1} / n
\end{aligned}
$$

Solving for the optimal $\left(a_{1}, b_{1}, c_{1}, d_{1}\right)$ is a relatively straightforward process. Once they are found, the maximum hkelihood estimate for $N_{1}$ is 


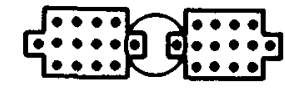

(a) EDGE TYPE o. (REGULAR EDGE)

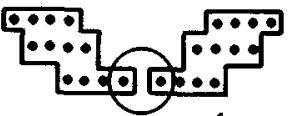

(d)

EDGE TYPE
(T CORNER) (b)

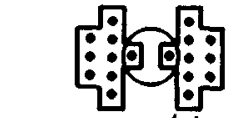
(LINE)

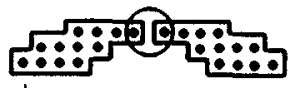

(c) EDGE TYPE $\%$ (T CORNER)

Fig 4 Typical neighborhoods for edge detection

$$
P_{1}=1 / \sqrt{ }\left(2 \pi^{n}\right) \cdot \sigma_{1}^{n} \cdot e^{-n / 2} .
$$

Hence we have the expression that tests for an edge the following way: If

$$
V_{0}^{m+n} /\left(V_{1}^{n} V_{2}^{m}\right) \geq K^{2},
$$

decide for $H_{1}$; otherwise decide for $H_{0}$.

Note that $(x, y, z)$ may be replaced by $(l, j, g)$ in regular black and white pictures, in which case we have a regular picture edge operation that can handle edges of type (b) in Figure 3. Somewhat similar applications have been reported [21 and 4] for detection of gradient edges (Figure $3(\mathrm{~b})$ ) This edge operator has not yet been incorporated in our system.

\section{Neighborhood Selection}

In the previous discussion on decision criteria, we deliberately omitted the question of how to choose the test neighborhoods. This is another variant of the properties that we want the edges to have. The edge value for a vertical edge between two horizontally adjacent points is taken to be the strongest case for an edge computed on the four pairs of neighborhoods (a)-(d) in Figure 4. Taking the maxımum of the maximum likelıhood ratio estımate for an edge among the four values computed for the four neighborhoods is similar to the approach advocated in [6].

A completely symmetric configuration is used to measure the confidence value of a horizontal edge unit between two vertically adjacent points. The choice of neighbors is of an experımental nature, and it worked for our problems. Other problem-dependent neighborhood choices are possible, and they will work for the specific edge structure in mind, as shown by the examples in Figure 5 . In choosing the size of a neighborhood a reasonable balance between noise and size of object should be achieved. The bigger the neighborhoods the less sensitive to noise the decision will be, but the small objects may be lost.

At this point it is worthwhile to refer to the edge detector developed by Hueckel [13]. He found an elegant technique that can be used to compute the best fitting 2-D step function.

is defined over a disk

$$
S T E P_{a, b, c, d, e}(l, j)= \begin{cases}d & \text { if } a l+b j \geq c \\ e & \text { if } a l+b j<c\end{cases}
$$

$$
\operatorname{DISK}\left(i_{0}, j_{0}, \gamma\right) \triangleq\left\{(i, j) \mid\left(i-i_{0}\right)^{2}+\left(j-J_{0}\right)^{2} \leq \gamma\right\},
$$

which corresponds to an edge line $a l+b_{j}=c$ where the brightness on one side is $d$ and on the other $e$. The step function is selected in an attempt to minimize the expression for a given signal $g(i, j)$ in the disk,

$$
\sum_{(2, j) \in D I S K}\left(g(i, j)-S T E P_{a, b, c, d, e}(i, j)\right)^{2},
$$




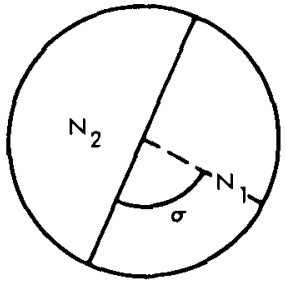

GENERAL EDGE ORIENTATION DETECTOR IN DISK COMPUTED FOR FINDING OPTIMAL ORIENTATIONS, DEPENDING ON THE DESIRED ANGULAR RESOLUTION

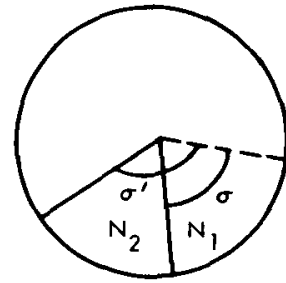

CORNER DETECTOR $\sigma^{\prime}$ AND $\sigma$ TAKEN TO BE TYPICAL ANGULAR RESOLUTIONS

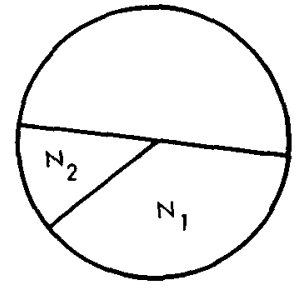

T CORNER DETECTOR

Fig 5 Extended neighborhoods set

over all possible step functions. He took the parameters of $a, b, c, d, e$ to be the parameters of the "best possible" edge passing through the disk. The edge value was then defined as $|d-e| / D I S$, which is a different measure than ours. An efficient method of finding good approximation of those parameters was developed Since our measure of edge strength is more complicated, it is unlıkely that an elegant and simple way of finding an optimal edge through a disk using our measure of edge strength is achievable However, given a suggested edge structure, our approach can be used immediately to provide a model driven confidence evaluation in the existence of the suggested edge. For the suggested $(a, b, c, d, e)$ edge parameter, let

$$
\begin{aligned}
& N_{2}=\sum_{\substack{a,+b) \geq c \\
(2, n \in D I S K}} 1, \quad \mu_{2}=d, \\
& \sigma_{2}^{2}=\sum_{\substack{a_{1}+b j \geq c \\
(i, j) \in D I S K}}(g(i, j)-d)^{2} / N_{2} ; \\
& N_{1}=\sum_{\substack{a,+b j<c \\
(\imath, j) \in D I S K}} 1, \quad \mu_{1}=e, \\
& \sigma_{1}^{2}=\sum_{\substack{a \\
a+b b_{j}<c \\
(\imath, j) \in D I S K}}(g(l, J)-e)^{2} / N_{1} ; \\
& N_{0}=N_{1}+N_{2} \text {, } \\
& \mu_{0}=\left(N_{2} \cdot \mu_{2}+N_{1} \cdot \mu_{1}\right) / N_{1}+N_{2}, \\
& \sigma_{0}^{2}=\sum_{(t, j) \in D I S K}\left(g(l, J)-\mu_{0}\right)^{2} / N_{0} .
\end{aligned}
$$

Then

$$
\text { STRENGTH }=\left(\sigma_{0}^{2}\right)^{v_{1}} /\left(\sigma_{1}^{2}\right)^{V_{1}}\left(\sigma_{2}^{2}\right)^{N_{2}},
$$

which uses again the theoretical superior maxımum lıkelıhood test.

\section{Locking on a Detected Edge}

The computed edge value is usually not sufficient to determine the location of the edges. The values that are computed usually look like those in Figure 6

One way of forcing the edge to be well defined is to constrain it to be a local maximum in addition to having a confidence value higher than a certain threshold. This is, of course, extremely important for locking on the center of the edge (see [14, p. 382]). Usually there is still some local ambiguity on the location of the edge, and for many practical reasons it is better to treat the area around an edge as ambiguous. The source of the problems here is that because of computing time constraints it is impossible to find a global optimum for edge lines using all avallable data, and it is necessary to use only local information for evaluating the edge units at this level. In our system the decision concerning the exact location of the edge was left for the region grower described in Section 7. Figure 7 illustrates the possible 2-D ambiguity.

The search for a maximum may be used for special purpose edge detection. For instance, if we look only for one dark stripe crossing a white background, forcing the 


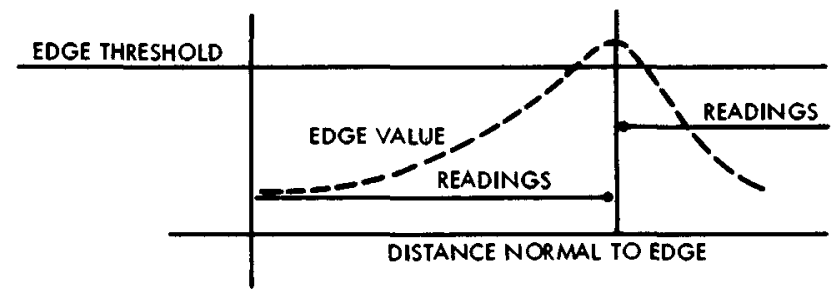

Fig 6 An ideal edge value cross section

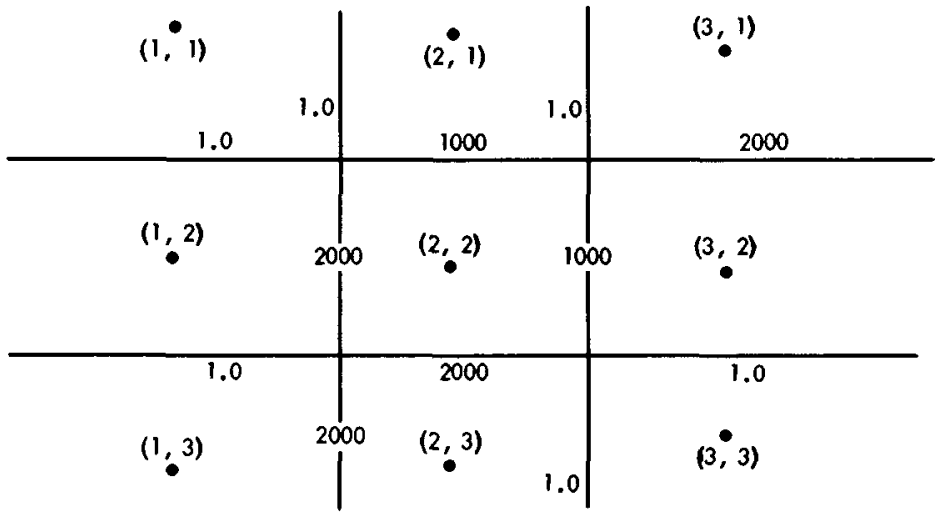

Fig 7 Region growing ambiguity example The $(l, j)$ are point numbers and the values are edge unt values Clearly points $(1,1)(1,2)(1,3)(2,1)(3,1)$ should be in one region and $(3,2)(3,3)(2,3)$ in another, but where $(2,2)$ should be is totally ambiguous (assuming that single point regions are not allowed)

edge to be the absolute maximum or minimum on a horizontal line in the image (keeping track of the direction of the change) will supply the approprate pair of edges on each of the horizontal lines.

\section{Region Growing}

The application of an edge detector results in two new matrices in additıon to the matrix $\mathbf{V}(i, j)$ of raw data. The first is $E V(i, j)$, which is the measure of the confidence that there is an edge unit between $(i, J)$ and $(l, j+1)$; the second is $E H(i, j)$, which measures the confidence that there is an edge unit between $(i, j)$ and $(i+1, j) . E V(i, j)$ and $E H(i, j)$ may include extra bits as determıned by the direction of the change on that suggested edge unit.

This output as it stands is not sufficient for application of pattern recognition and varıous picture quantıtatıve analysis tasks. Outlınes of objects are needed to recognize features One way of achieving these is to use a region grower that will outline objects by clustering points into regions This approach has been used for picture analysis $[5,2,11$, 24] The basic conclusion of these works is that without using semantic information, which is the knowledge of the subject of the picture, clustering cannot create perfect outlınes. More recent work [8, p. 324, and 12] has introduced new techniques of clustering that provide more flexibility and may upgrade clustering performance for images.

Here we introduce a new algorithm for clustering based on a search for "valleys" of edge values in a picture. If random access is allowed, a relatively simple algorithm that starts and climbs from local minima of edge values can be implemented. Because of a lack of storage capacity on our minicomputer, and in an attempt to use data as it is sequentıally digitızed from the vıdeo signal, a one-pass algorithm to generate regions corresponding to valleys was implemented. This is the first tıme to our knowledge that this approach has been used. 
Most works on region growing (ours included) lack the capacity to make use of the shape of the growing object. An alternative approach to region growing is "edge following" $[17,15,10$, and 3$]$. The basic idea in edge following is to detect a discontinuity, trace it, and in this way define edge lines. Unfortunately the work in edge following lacks an effective way of tying region shape properties into their decision processes and output.

Let us start by describing a one-pass algorithm that transforms the edge into data structures of regions, boundaries, closed cracks, and open cracks, creating as byproducts two arrays, $F H(i, j)$ and $F V(i, j)$, where $F H(i, j)$ means that the program puts an edge unit between $(i-1, j)$ and $(i, j)$ and $F V(i, j)$ means an edge unit between $(i, j)$ and $(i, j-1)$.

To facilitate the description of the decision mechanısm for placing edges, we need to define a few new terms. Let $T>0$ be the edge confidence threshold; then:

(1) $d$ is the distance between two adjacent grid points:

$$
\begin{aligned}
& d((i, j),(i-1, j)) \triangleq d((i-1, j),(i, j)) \triangleq(\text { if } E H(i, j) \leq T \text { then } 0 \text { else } E H(i, j)) . \\
& d((i, j),(i, j-1)) \triangleq d((i, j-1),(i, j)) \triangleq(\text { if } E V(i, j) \leq T \text { then } 0 \text { else } E V(i, j)) .
\end{aligned}
$$

(2) $\operatorname{Reg}(i, j)$ is the region to which the point $(i, j)$ belongs. $(\operatorname{Reg}(i, j)$ is not defined to all points until the program is finıshed.)
(3) $\operatorname{Val}(i, j)=$
$\operatorname{Min}$
$d((i, j),(k, m))$.

There is no edge unit between $(i, j)$ and $(k, m)$. This value will be $+\infty$ if $(i, j)$ is the only point in its region.

(4) $\operatorname{Val}\left(\operatorname{Reg}_{1}\right)=\operatorname{Min}_{\substack{(i, j) \\ \operatorname{Reg}(i, j)=\operatorname{Reg}_{1}}}(\operatorname{Val}(i, j))$

(5) A point $P$ will be the minimum point for its region if $\operatorname{Val}(P)=\operatorname{Val}(\operatorname{Reg}(P))$.

The algorithm is designed so that at each state there is always a nondecreasing edge distance value path from each minımum of any region to any other point in the region and the path enters that point from its minimum direction.

That is, If $P$ and $Q$ are two points such that $\operatorname{Reg}(P)=\operatorname{Reg}(Q)$ and $\operatorname{Val}(P)=$ $\operatorname{Val}(\operatorname{Reg}(P))$, then there is a path $\left(x_{1}, x_{2}, \ldots, x_{n}\right)$ such that

(a) $x_{1}=P, x_{n}=Q$

(b) $\operatorname{Reg}\left(x_{2}\right)=\operatorname{Reg}(P), i=1, \ldots, n$;

(c) $x_{\imath}$ adjacent to $x_{\imath+1}, d\left(x_{\imath+2}, x_{\imath+1}\right) \geq d\left(x_{\imath+1}, x_{\imath}\right)$;

(d) $d\left(x_{n}, x_{n-1}\right)=\operatorname{Val}\left(x_{n}\right)$.

We say that if such a path exists, $Q$ is reachable from $P$. That is, two points are in the same region if you can get from one to the other in a path that does not cross a ridge of edge values.

\section{Algorithm Description}

The program scans the image line by line from left to right The scanning is such that when point $(i, j)$ is processed, the program has already worked on all points $\left(i_{1}, j_{1}\right)$ such that $\left(j_{1}<j\right)$ or $\left(j=j_{1}\right.$ and $\left.i_{1}<i\right)$ At each point one of the conditions in Figure 9 exists, and the algorithm treats them as described in Figure 9 to grow the regions, boundaries, and crack lines.

Assume the program is processing point $(i, j)$.

Let $D_{1}$ be a Boolean variable set to true if the program is not going to put an edge unit between $(i, j)$ and $(l, j-1)$ and set to false otherwise, and let $D_{2}$ be a Boolean variable set to true if the program is not going to put an edge unit between $(i, j)$ and $(i-1, j)$ and set to false otherwise. Let $R_{1}=\operatorname{Reg}(i, j-1)$ and $R_{2}=\operatorname{Reg}(i-1, j)$ (see Figure 8).

The decision on the values of $D_{1}$ and $D_{2}$ is described by the following Algol-like program: 


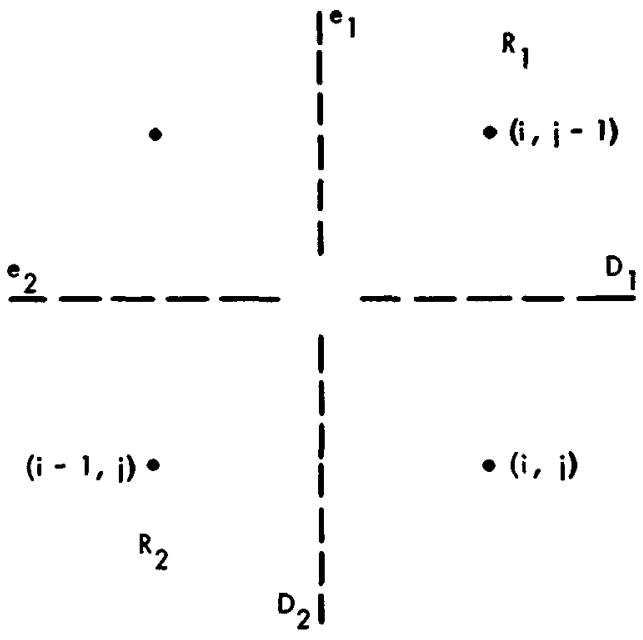

FIG 8 Algorithm terms definition

\section{begin}

Boolean good-down, bad-down $n_{1}, u p_{1}$, good-down $n_{2}$, bad-down $n_{2}, u p_{2}$,

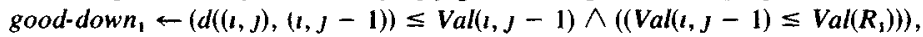

Comment good-down, is true if point $(l, j)$ is going to become a new minimum for $R_{1}$ (the region above) and It is adjacent to an old minimum, hence any point of $R_{1}$ reachable from the old adjacent minimum will be reachable from the new,

bad-down $\leftarrow \leftarrow(d((t, J),(t, j-1))<\operatorname{Val}(t, J-1)) \wedge\left(\left(\operatorname{Val}(t, j-1)>\operatorname{Val}\left(R_{1}\right)\right)\right),$.

Comment This variable is true if $(t, j)$ is not reachable from all minıma of $R_{1}$ going through $(i, J-1)$, $u p_{1} \leftarrow d((t, j),(t, J-1)) \geq \operatorname{Val}(t, J-1)$,

Comment This variable is true if point $(t, J)$ is reachable from any minımum of $R_{1}$ by continuing the path that leads from that minimum to $(i, j-1)$,

good-down $n_{2} \leftarrow(d((t, J),(t-1, \jmath)) \leq \operatorname{Val}(t-1, \jmath)) \wedge\left(\left(\operatorname{Val}(t-1, J) \leq \operatorname{Val}\left(R_{2}\right)\right)\right)$;

Comment This variable is true if point $(l, j)$ is going to be a new minimum for $R_{2}$ (the region minimum, to the side) and is adjacent to an old minımum of $R_{2}$, hence any point reachable from the adjacent old minımum will be reachable from $(t, J)$,

bad-down $n_{2} \leftarrow(d((t, J),(t-1, J))<\operatorname{Val}(t-1, J)) \wedge\left(\operatorname{Val}(t-1, j)>\operatorname{Val}\left(R_{2}\right)\right)$

Comment This variable is true if $(i, j)$ is not reachable from all minima of $R_{2}$ through $(l-1, J)$, $u p_{2} \leftarrow d(t, j),(t-1, j) \geq \operatorname{Val}(t-1, j)$,

Comment This variable is true if point $(t, J)$ is reachable from any minıma of $R_{2}$ by continuing the path that leads from that minımum to $(i-1, j)$,

If good-down $n_{1} \wedge$ good-down 2 then $D_{1} \leftarrow D_{2} \leftarrow$ true

else

If good-down $1 \wedge$ good-down 2 then $D_{1} \leftarrow D_{2} \leftarrow$ true

else

If good-down $n_{1} \wedge$ bad-down $n_{2}$ then begin $D_{1} \leftarrow$ true,

$D_{2} \leftarrow$ false, end else if good-down $1 \wedge u p_{2}$ then

begin

if $d((t, J),(l, J-1)) \geq d(t(i, J),(t-1, J))$

then $D_{1} \leftarrow D_{z} \leftarrow$ true

else begin $D_{1} \leftarrow$ true, $D_{2} \leftarrow$ folse, end,

end

else if bad-down then begin if good-down $\vee u p_{2}$ then begin

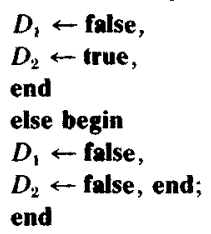

else if $u p_{1} \wedge \operatorname{good}-d o w n_{2}$ then begin

if $d((t, j),(l-1, j)) \geq d((i, J),(i, J-1))$

then $D_{1} \leftarrow D_{2} \leftarrow$ true 
else begin $D_{2} \leftarrow$ true, $D_{1} \leftarrow$ false, end,

end

else if $u p_{1} \wedge u p_{2}$ then, if $R_{1}=R_{2}$ then $D_{1} \leftarrow D_{2} \leftarrow$ true else

if $d((t, j),(t-1, J)) \geq d((t, j),(t, J-1))$

then begin $D_{1} \leftarrow$ true, $D_{2} \leftarrow$ false, end

else begin $D_{1} \leftarrow$ false; $D_{2} \leftarrow$ true; end

end

Comment In that case only one of $D_{1}$ and $D_{2}$ can be true, otherwise we cannot guarantee entrance through

a minimum value from all minıma of both $R_{1}$ and $R_{2}$,

else if $u p_{1} \wedge$ bad-down $n_{2}$ then begin $D_{1} \leftarrow$ true, $D_{2} \leftarrow$ false; end

$\operatorname{Val}(t, \jmath) \leftarrow \infty$;

if $D$, then begin

$\operatorname{Val}(l, J-1) \leftarrow \operatorname{Min}(d((t, J),(t, J-1))), \operatorname{Val}(t, J-1))$

$\operatorname{Val}(t, J) \leftarrow d((\iota, j),(i, j-1))$,

$\operatorname{Val}\left(R_{1}\right) \leftarrow \operatorname{Min}\left(\operatorname{Val}\left(R_{1}\right), \operatorname{Val}(\iota, J)\right)$,

end,

If $D_{2}$ then begin

$\operatorname{Val}(t-1, j) \leftarrow \operatorname{Min}(d((t, j),(t-1, j)), \operatorname{Val}(t-1, j))$,

$\operatorname{Val}(t, J) \leftarrow \operatorname{Min}(\operatorname{Val}(t, j), d((t, j),(t-1, j)))$,

$\operatorname{Val}\left(R_{2}\right) \leftarrow \operatorname{Min}\left(\operatorname{Val}\left(R_{2}\right), \operatorname{Val}(t, j)\right) ;$

end,

If not $\left(D_{1} \vee D_{2}\right)$ then $\operatorname{Val}(\operatorname{Reg}(t, J)) \leftarrow \infty$,

The $e_{1}$ and $e_{2}$ (see Figure 8) may exist or not, and as a result there are four starting conditions. The program may put $D_{1}, D_{2}, D_{1}$, and $D_{2}$ or none of them, and hence there are 16 cases in a point. (See Figure 9 for a brief description of the different cases.)

\begin{tabular}{|c|c|c|c|}
\hline $\begin{array}{l}\text { REGION, } \\
\text { REGION, } \\
\bullet \\
\text { REGION, } \\
\text { START NEW REGION } \\
\text { (REGION })_{2} \text {. PUT TWO EDGE } \\
\text { UNITS STARTING BOUND- } \\
\text { ARY LINE BETWEEN } \\
\text { REGION, AND REGION }\end{array}$ & $\begin{array}{c}\text { REGION, REGION, } \\
\text { REGION, REGION, } \\
(1,1) \\
\text { ADO }(1,1) \text { TO REGION, }\end{array}$ & $\begin{array}{l}\text { REGION, } \\
\text { REGION, } \frac{\text { REGION }}{\text { REGION, }}(1) \\
\text { INITIATE AN OPEN } \\
\text { CRACK EDGE LINE START- } \\
\text { ING BETWEEN }(1,1)(1,1-1) \\
\text { INSIDE REGION, }\end{array}$ & $\begin{array}{l}\text { REGION, REGION, } \\
\text { REGION, | REGION, } \\
\bullet \\
\text { INITIATE AN OPEN CRACK } \\
\text { STARTING BENWEN (1) } 1) \\
(1-1,1) \text { INSIOE REGION, }\end{array}$ \\
\hline \begin{tabular}{l|l} 
REGION, $_{1}$ & $b_{1}^{\text {REGION }}$, \\
REGION, & $\bullet(1,1)$ \\
MAKE $b_{1}$ AN OPEN CRACK. \\
MERGE REGION, AND \\
REGION ${ }_{2}$ AND ADD $(1,1)$ \\
TO THE UNION
\end{tabular} & 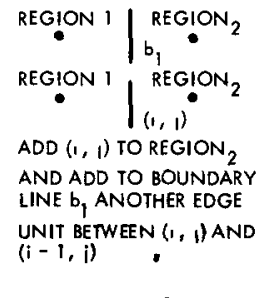 & 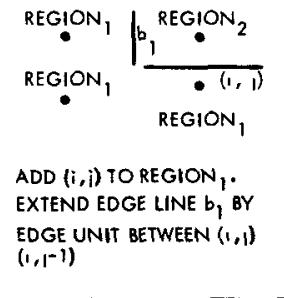 & $\begin{array}{l}\text { CREATE NEW REGION } \\
\text { CONTAINING ONIY }(\dot{1}, 1) \text {. } \\
\text { CREATE WO BOUNDARY } \\
\text { EDGE UNES } \mathrm{b}_{2} \text { AND } b_{3}\end{array}$ \\
\hline $\begin{array}{l}\text { REGION, } \\
b_{1} \text { REGION, } \\
\text { REGION } \\
\text { MAKE } b_{1} \text { AN OPEN CRACK. } \\
\text { MERGE REGION AND } \\
\text { REGION AND ADD }(1,1) \\
\text { TO THE UNION }\end{array}$ & $\begin{array}{l}\text { REGION } \\
\text { REGION } \\
\text { RDD }(1,1) \text { REGIO REGION } \\
\text { AND ADD TO BOUNDAN } \\
\text { LINE } b_{1} \text { ANOTHER EDGE } \\
\text { UNIT BETWEEN }(1,1) \text { AND } \\
(-1,1)\end{array}$ & $\begin{array}{l}\text { REGION, REGION, } \\
\text { REGION }, \text { REGION, }_{1} \\
\text { ADD }(1,1) \text { TO REGION, } \\
\text { EXTENO EDGE LINE } b_{1} \text { BY } \\
\text { EDGE UNIT BETWEEN }(1,1) \\
(1-1,1)\end{array}$ & 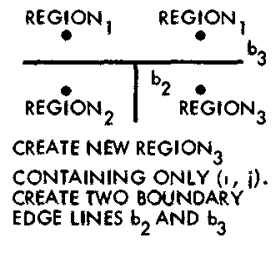 \\
\hline 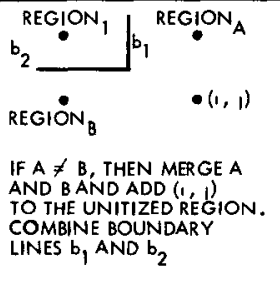 & 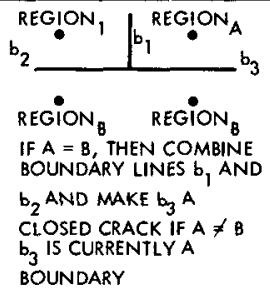 & 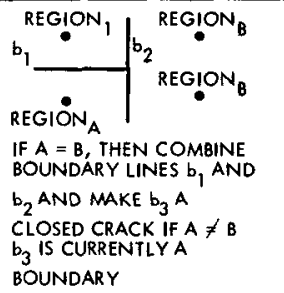 & \begin{tabular}{l|l}
$\begin{array}{l}\text { REGION, } \\
b_{1}\end{array}$ & $b_{2}$ REGION \\
REGION & $b_{3}$ REGION \\
START NEW REGION, \\
REGION, AND TWO \\
BOUNDARY LINES $b_{3}$ \\
AND $b_{4}$
\end{tabular} \\
\hline
\end{tabular}

Fig 9 The different region growing decisions 

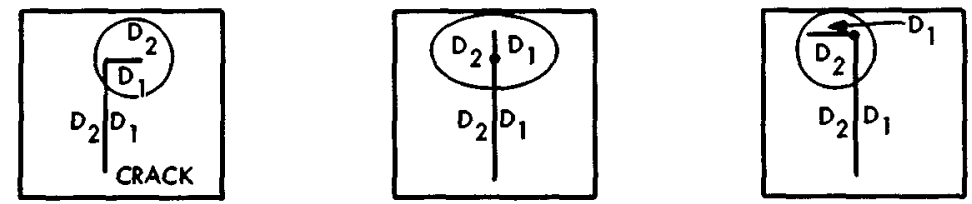

THE 3 OPTIONS TO EXTEND AN OPEN CRACK AND THE CORRESPONDING ASSUMPTION ON DISTRIBUTING

FIG 10 The three options to extend an open crack and the corresponding assumption on distributing

Merging of two regions may always result in transformation into a crack of a previously common boundary of the two regions. In general each operation of the region grower is fairly elaborate. The data structure used is not described in this paper, but it is essentially the same data structure described in [24] with slight modification to include edge line representation through chain encoding.

This one-pass algorithm is local and requires relatively small core resident data. However it does not create maximal regions with respect to directionality of the region growing. On the other hand, it is relatively simple and fast when other algorithms are considered. The maximality problem may be easily corrected if backup is allowed. Note also that the threshold $T$ plays a very small role in defining the output of the algorithm.

\section{Simplification of the Result of Basic Region Growing}

There are two straightforward options for simplifying the output of the one-pass region grower: (1) take all regions that are too small to be interesting and melt them into their closest neighbor (the distance between two regions will be defined later in the paper); (2) take all short cracks that are weak (strength of the edge line will be defıned later) and delete them. Of course the threshold below which a crack is weak and a region is small is a function of how much we want to elaborate the task of the image analysis and is defined heuristically. In fact, in the current implementation all cracks are deleted since the edge operator is sensitive enough for our purposes.

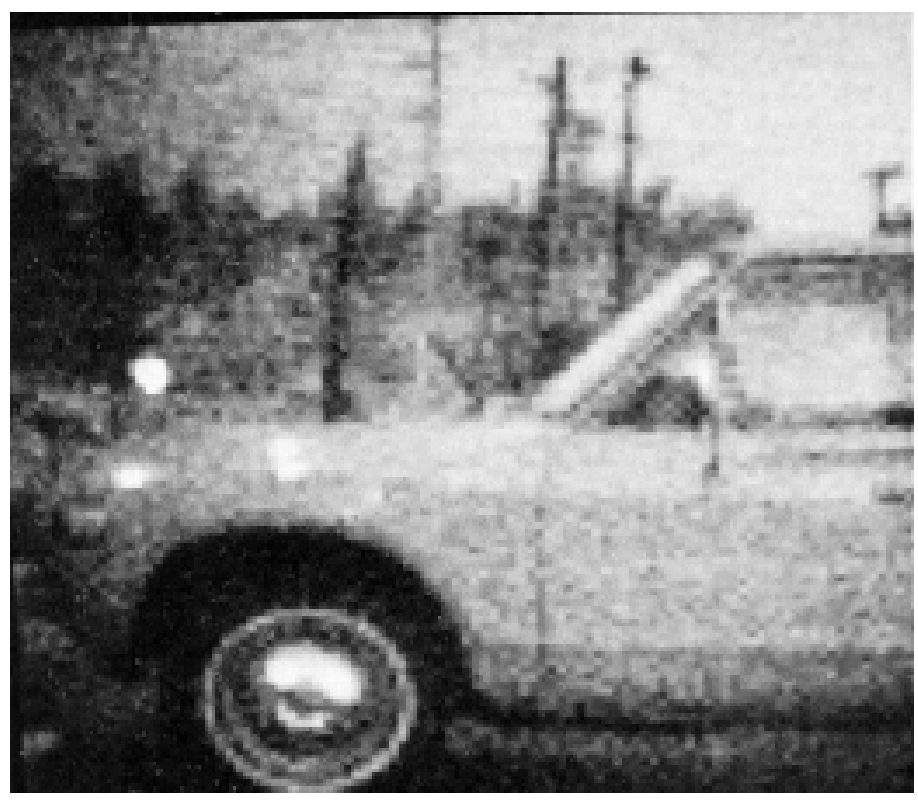

Fig. 11 Onginal 


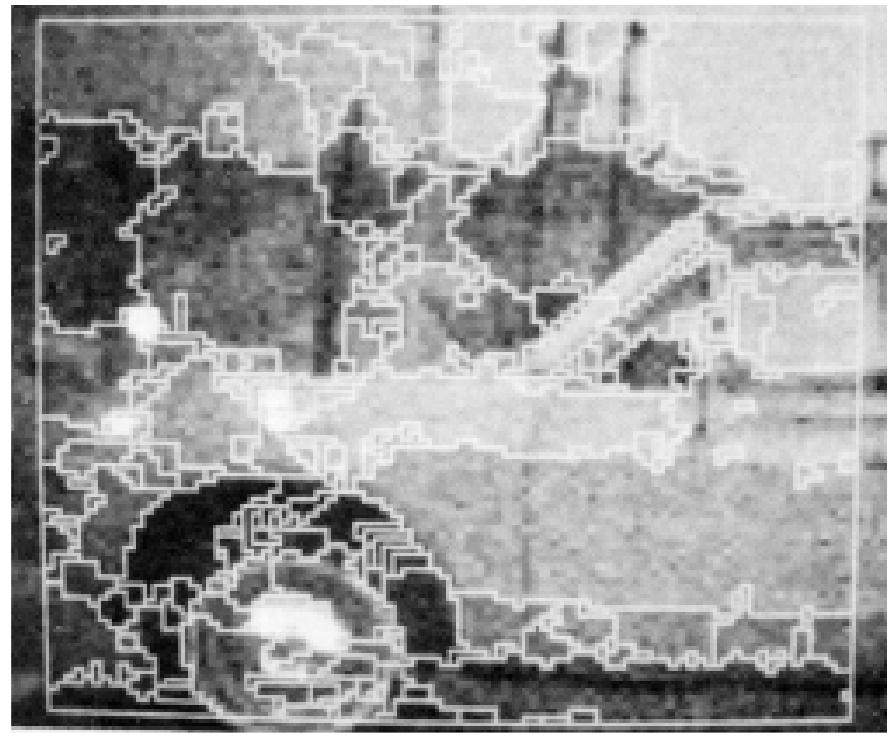

FIG. 12. Region growing based on proposed region grower (Section 7) using the edge evaluation of Section 3 with default thresholds

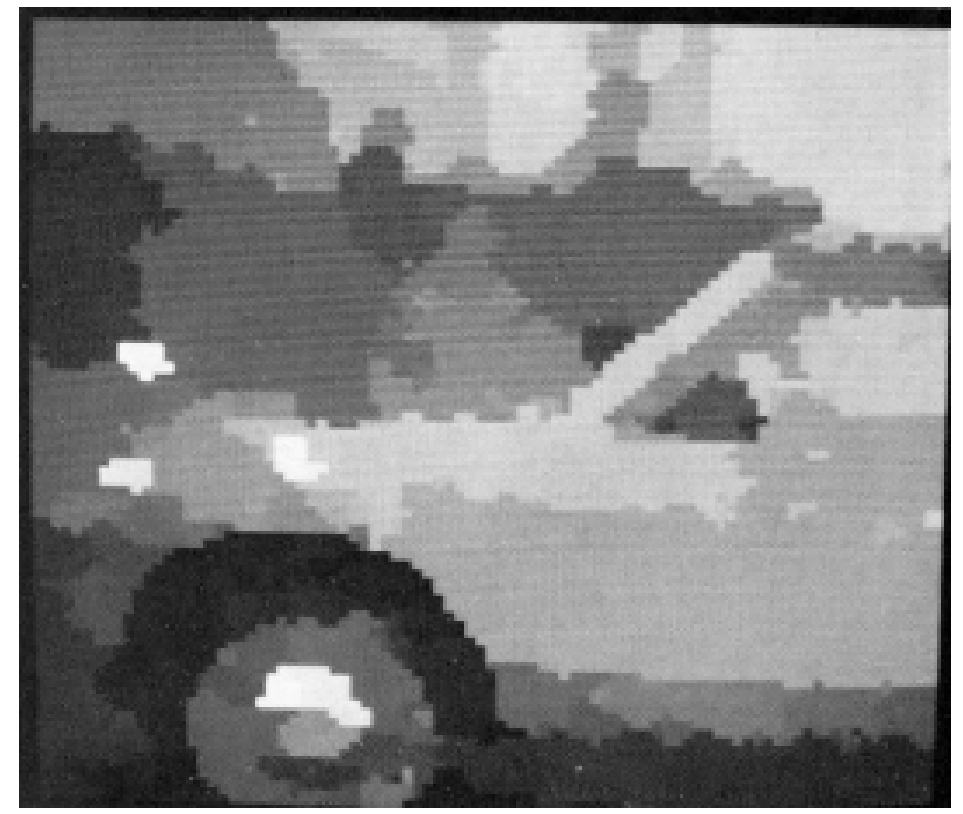

FIG 13. Reconstruction of the picture from the information contained in the regions of Figure 12

\section{Growing Open Cracks Into Closed Cracks}

At the present tıme we just obtain the cracks within regions and mark them as such. In the future one may look for ways of closing them to define finer regions. One possible way of closing open cracks is to grow them in length from their open end until the 


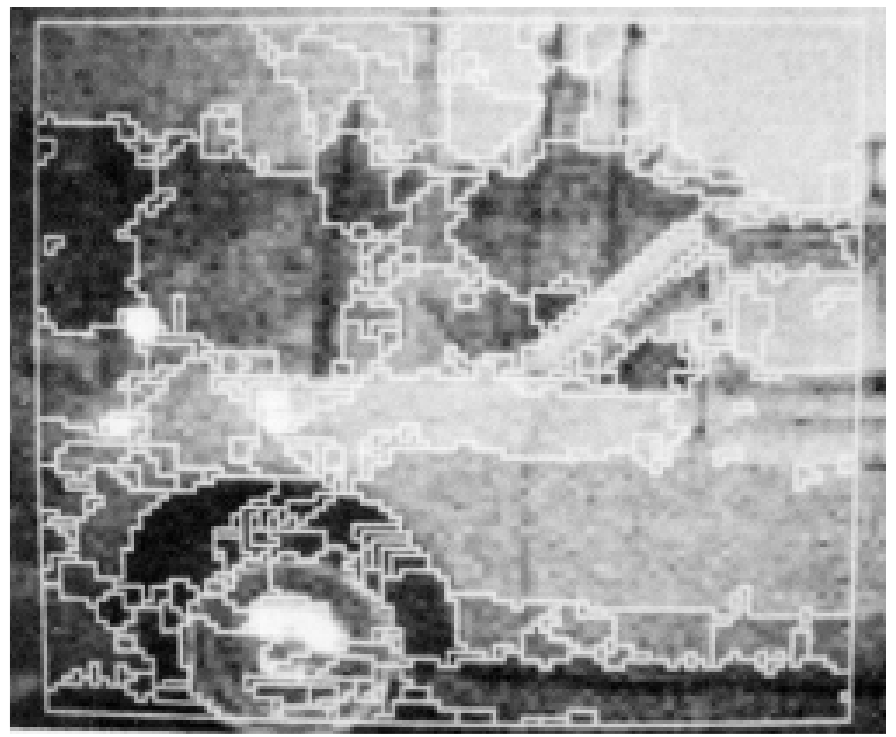

Fig. 14 Meltıng regions from Figure 12 using default threshold on second pass

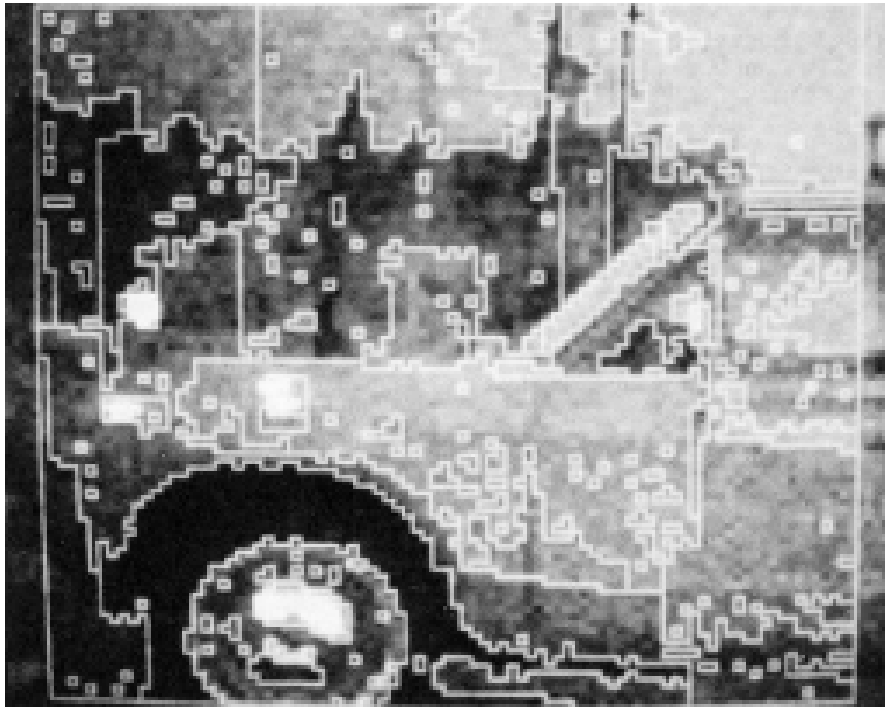

Fig. 15 Growing regions with the only constraint that maximum range of gray level in a region is less than 20 (20 selected as best for that image)

extended edge line meets already existing edge lines and closes. On the open end in each step there are three choices of where to extend the edge line: go straight ahead, turn left, or turn right. The decision as to which direction to take will minımize the cost of closing the open crack, where the cost is defined heuristically. One possible choice is as follows:

Given the original crack, define two distributions that describe the properties on either side of the crack, $P_{\mathrm{D}_{1}}$ and $P_{\mathrm{D}_{2}}$. The cost of adding an edge unit will be the maximum likelihood ratio between the two assumptions:

$H_{0}$ : the two sides of the edge unit belong to the same side of the crack (the best chorce between $D_{1}$ on both sides of the extension and $D_{2}$ on both sides);

$H_{1}$ : there is a different distribution on either side chosen according to geometrical 


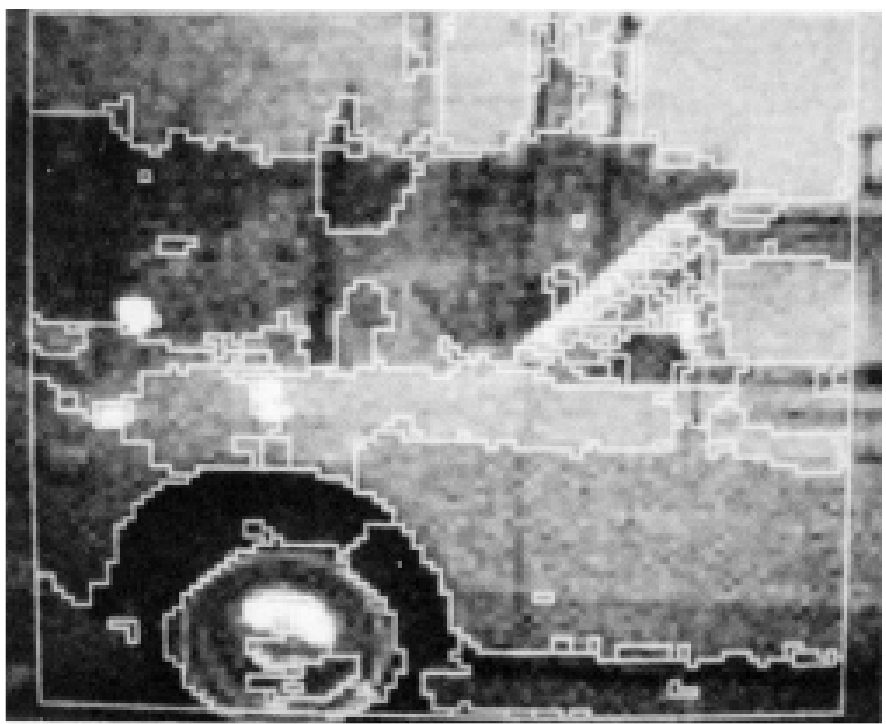

FIG 16 Region growing using $\left|\sum_{t=1}^{n}\left(X_{t}-Y_{t}\right)\right|$ as the edge value with the proposed one pass region grower Threshold which was selected manually as optional to that picture was set to $5 \cdot n$

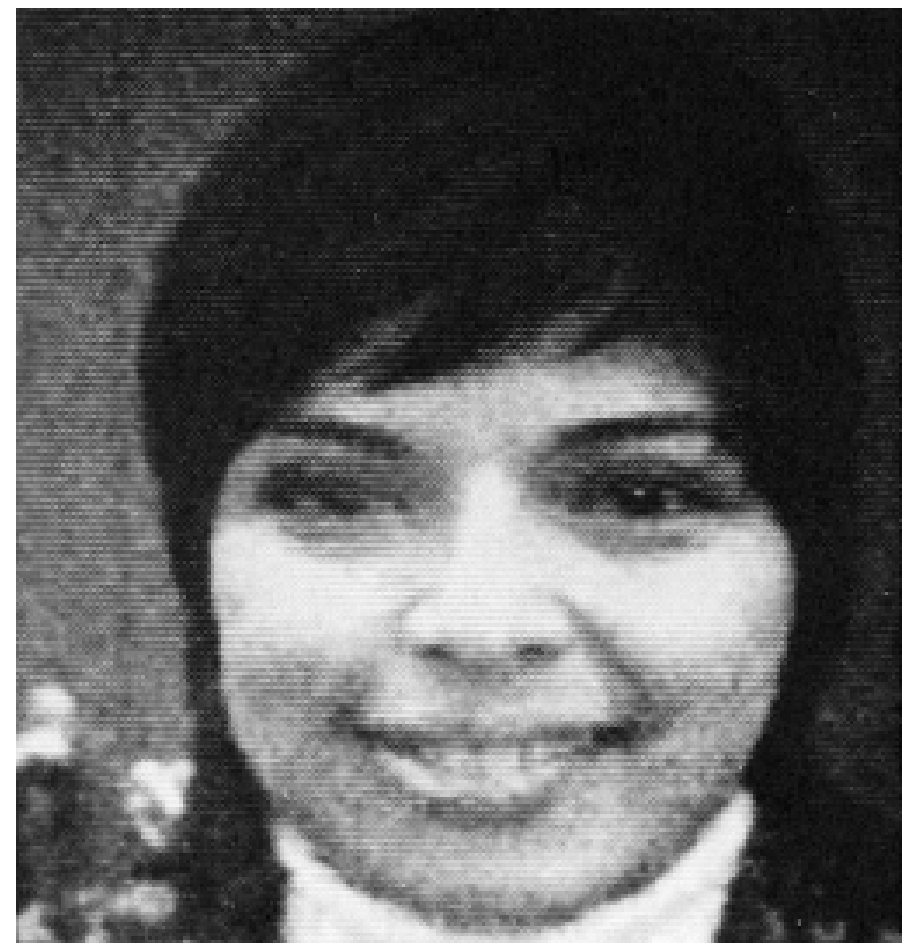

Fig 17 Origınal

constraint (Figure 10).

Cost $=P_{H_{0}} / P_{H_{1}}$.

Note that since the cost function is additive it can be used in conjuction with the shortest path algorithm [16, Ch. 3] to find the nearest (least expensive) path to a closing 


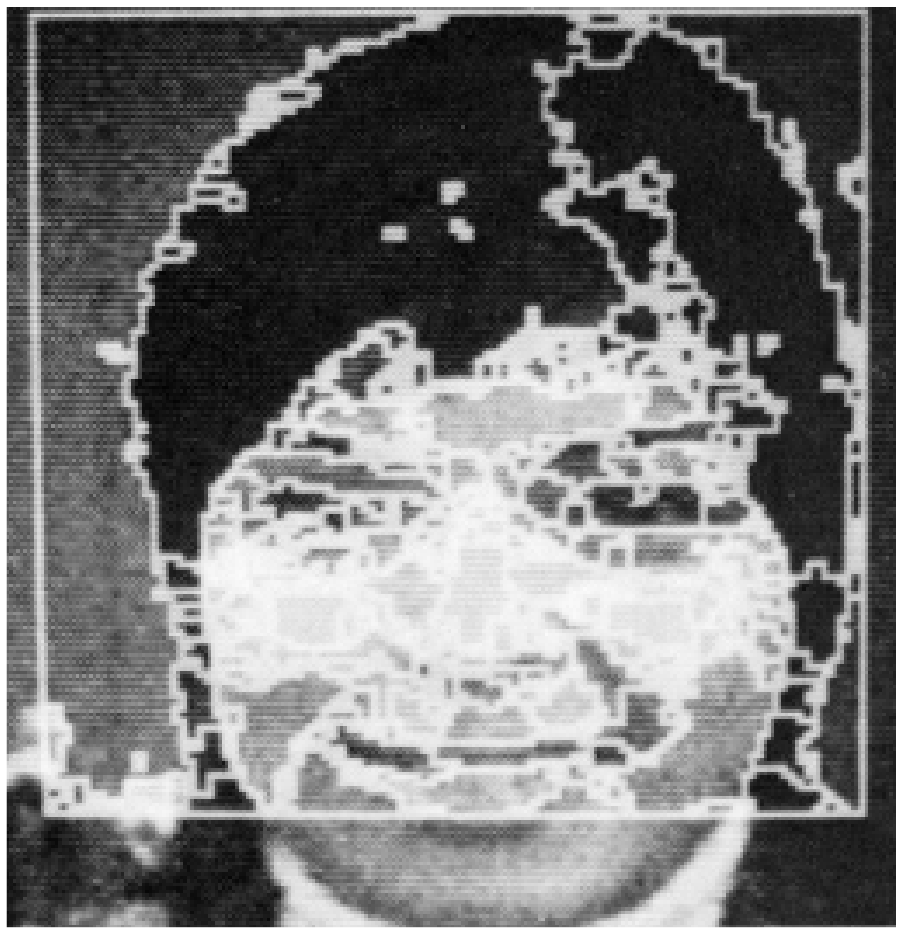

Fig 18 Region growing default parameters (like Figure 12)

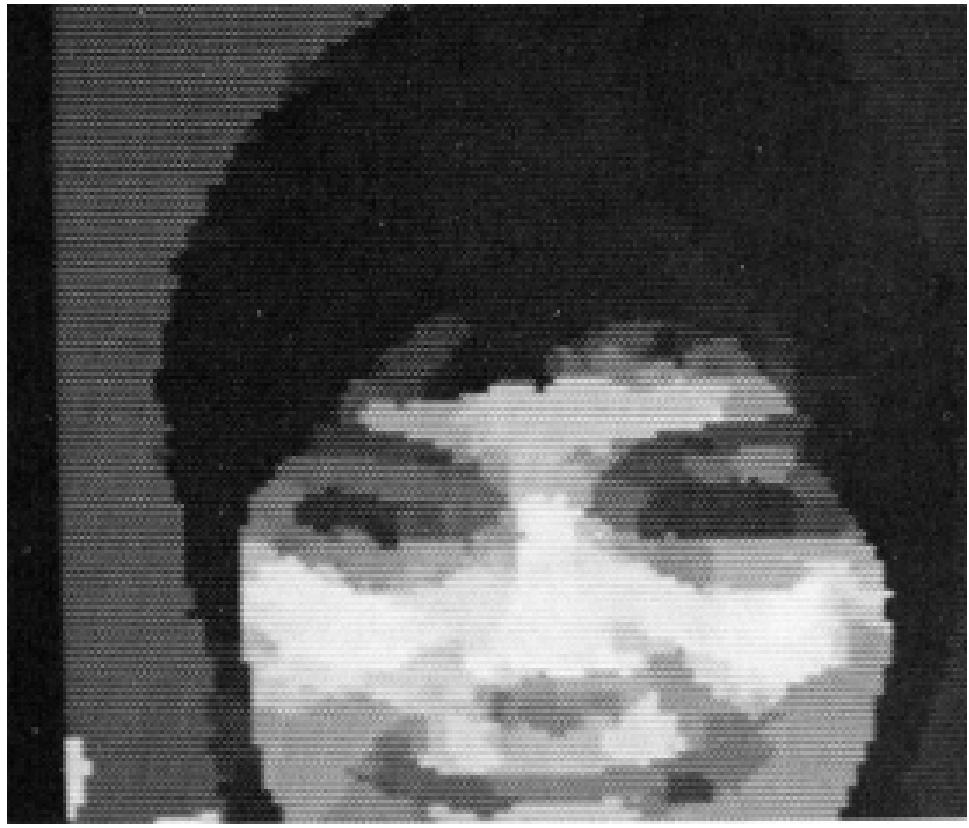

Fig 19 Reconstruction of Figure 18

edge unit. Reference [16] describes an application of the shortest path algorithm to edge extension under simpler constraints. This technique is immediately applicable to our different cost function and the different termination condition on the path. 


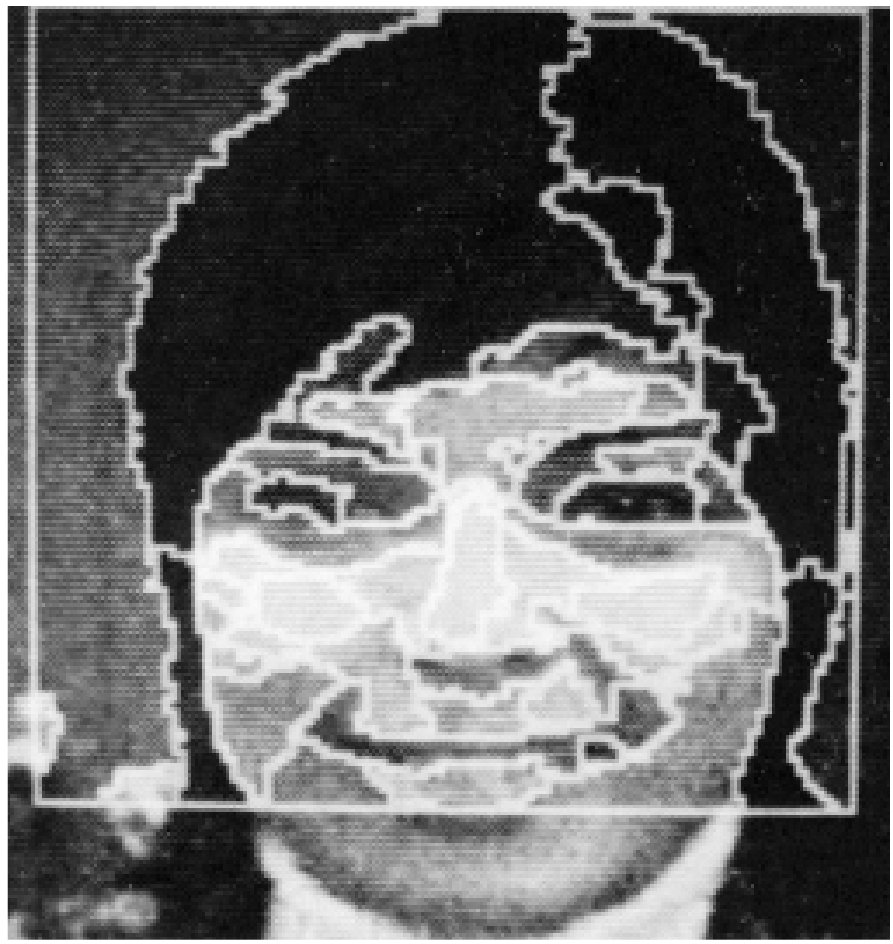

FIG 20 Meltıng second pass with default threshold applied to Figure 18

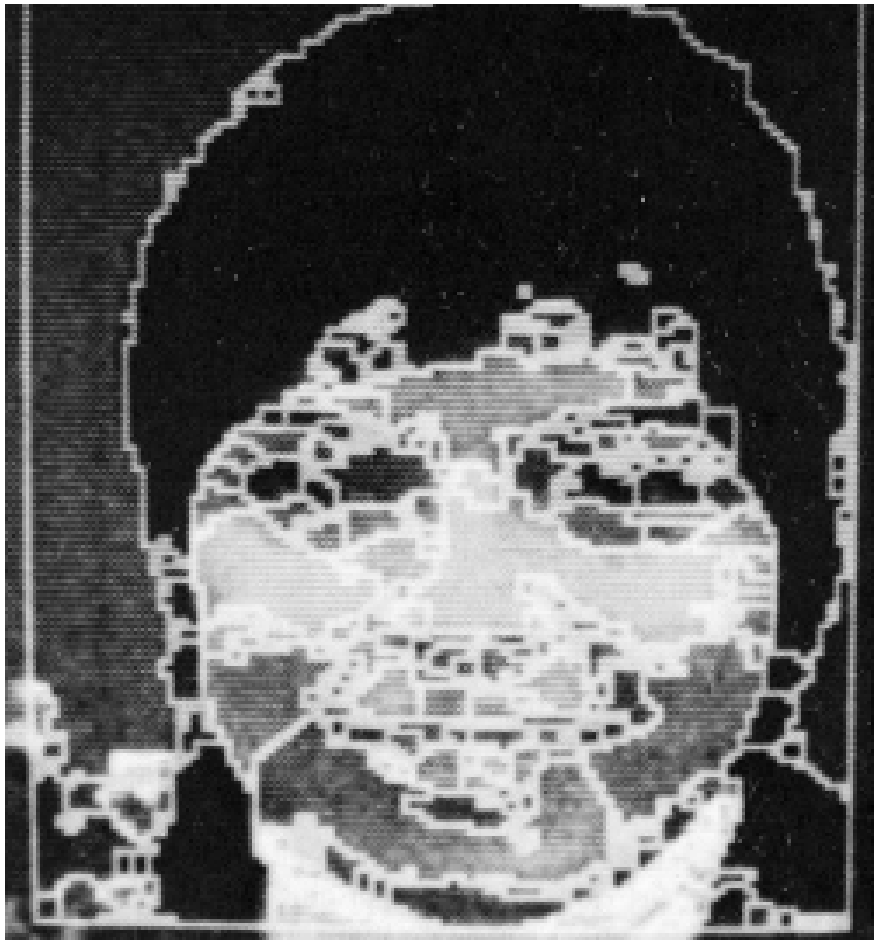

FIG 21 Region growing with edge values set to $\sum_{i=1}^{n}\left(X_{1}-Y_{i}\right)$ with threshold set to $8 \cdot n$ 


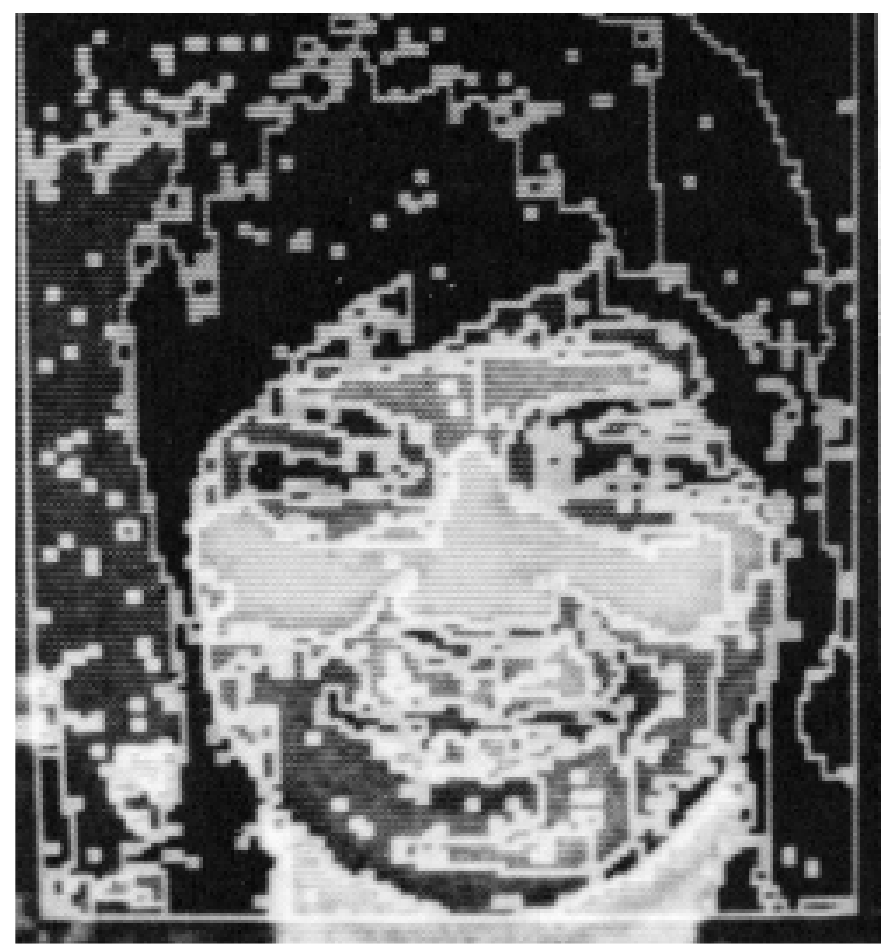

FIg 22. Region growing so that maximum range of gray levels within a region is less than 25

\section{Breaking a Region Into Two Around a Crack}

An alternative approach to breaking a region into two regions to make the crack into a part of a boundary is to use special purpose region growing. Assume that there is a crack in a regular gray level picture $\left(V(i, j) \in R_{1}\right)$ with readings with mean $\mu_{1}$ and variance $\sigma_{1}^{2}$ on a small neighborhood on one side of the crack and mean $\mu_{2}$ and variance $\sigma_{2}^{2}$ on the other side. Assume that the crack is inside region $R$; then we can break the points in $R$ into two classes, $C_{1}$ and $C_{2}$ :

$C_{1} \triangleq\left\{\begin{array}{l|l}(i, j) & \frac{1}{\sqrt{ }(2 \pi) \cdot \sigma_{1}} \cdot e^{-\frac{1}{\left(2\left(V(i, j)-\mu_{1}^{2}\right) / \sigma_{1}\right.}} \leq\left(1 / \sqrt{ }(2 \pi) \cdot \sigma_{2}\right) \cdot e^{-\frac{1}{3\left(V(i, j)-\mu_{2}^{2}\right) / \sigma_{2}}}\end{array}\right\}, C_{2} \triangleq R \sim C_{1}$.

Then we would expect $C_{1}$ to be on the first side of the crack and $C_{2}$ on the second side of the crack. Unfortunately it may turn out that $C_{1}$ or $C_{2}$ is not pathwise connected. As a result one of the connected components that border on the crack should be picked out. A more heuristic approach is to grow a region around each of the two sides of the crack, and to stop when a new point has a neighborhood that is more likely to belong to the other side. Then take the smaller of the two regions resulting and make it $C_{1}$; then $C_{2}$ will be $C_{2}=R-C_{1}$.

This algorithm can be used also to allow flexible human intersection in analyzing the scene. This can be done by allowing the operator to use cursor sample points of the two subregions of a region. The machine then defines the separating features of the two subregions and carries out the sequentation. [12] and [23] describe systems that automatically select the distinguishing features of subregions of a given region. The local structure around a crack provides the distinguishing features of the two sides, and implementing an automatic system for doing that should be relatively easy. Currently this option is not used in our system, but descending from down region to subregion is of great potential value. 


\section{Merging Regions}

This basic region grower utilizes local detection procedures. Better decisions are achievable (at least theoretically) by using more global information. The problem is how to use this additional information and stıll keep the program lean and fast. Research in this area has been reported [24] Our basic approach is to be oversensitive on the local pass and as a result to oversegment the picture. But then we take the output data (which is simple relative to the original picture) and simplify it We take pairs of regions with common boundaries and merge them into one To do that reliably, a confidence value that measures the confidence that the pair of regions are different is computed. Then we iteratively select the pair of regions with the lowest confidence of being different in the current structure, merge them, and update the structure. The confidence is dependent on two factors: (1) edge line strength (on the common boundary of the two regions), and (2) the difference of the properties inside the two regions. Both of these values are computed on the basis of assumptions similar to those used in the edge confidence evaluation. For instance, if we assume gray level readings and let $x_{i}, i=1, n$, be the readings on one region and $x_{i}^{\prime}, i=1, m$, be the readings at the other, then the second factor is

$$
\text { CONFIDENCE } \left.=V_{0}^{m+n} / V_{1}^{n} \cdot V_{2}^{m}\right)
$$

where

$$
\begin{array}{ll}
\text { (1) } \mu_{0}=\left(\sum_{i=1}^{n} X_{i}+\sum_{i=1}^{m} X_{i}^{\prime}\right) /(m+n), & \text { (4) } V_{1}=\left(\sum_{i=1}^{n}\left(X_{i}-\mu_{1}\right)^{2}\right) / n \\
\text { (2) } V_{0}=\left(\sum_{i=1}^{n}\left(X_{1}-\mu_{0}\right)^{2}+\sum_{i=1}^{m}\left(X_{1}^{\prime}-\mu_{0}\right)^{2}\right) /(m+n), \text { (5) } \mu_{2}=\left(\sum_{i=1}^{m} X_{i}^{\prime}\right) / m, \\
\text { (3) } \mu_{1}=\left(\sum_{i=1}^{n} X_{i}\right) / n, & \text { (6) } V_{2}=\left(\sum_{i=1}^{m}\left(X_{i}^{\prime}-\mu_{2}\right)^{2}\right) / m .
\end{array}
$$$$
\text { (5) } \mu_{2}=\left(\sum_{i=1}^{m} X_{i}^{\prime}\right) / m
$$

Results usıng only this factor are shown below. In [24] the local boundary properties are used to compute the edge values. The merging is stopped when the weakest boundary strength is more than a given threshold

\section{Results}

The suggested one-pass region growing algorithm driven by edge values was implemented on the General Automation SPC-16/75 minicomputer of the JPL robotics lab. The input picture is digitized into 256 gray levels from the black and white video signal of a Cohu camera. The noise variance is 2 , measured from repetitious readings of the same point in a sequence of images. A Ramtek display unit is interfaced with the minicomputer and is used to display the digitized picture in green. Boundary lines of regions are displayed in red over the original picture for performance evaluation.

All cracks are currently ignored. The threshold below which the edge value is truncated to 0 was fixed at 2000 in all the examples below. A system to set the threshold automatically to allow only 5 percent of the points of the image to have value over the threshold was scrapped in favor of an absolutely fixed threshold.

The output of the first pass is then passed to a region merger that reduces the number of regions also with a default fixed threshold (merge till $\log$ (confidence) is greater than or equal to 20). The compute time for a $200 \times 200$-pixel picture is approximately a minute for a program that is highly inefficient because of debugging aids.

The results shown in Figures 11-22 are encouraging. We believe that the use of planar fits (the gradient edge detector instead of the step edge detector) and the dynamic use of region features as they grow to upgrade performance of the region grower will result in 
even better performance. We found the region growing algorithm an important tool in scene analysis [25], and look forward to improving its performance.

Comparison of performance of the suggested region growing approach with two others is given. The furst alternative is the one-pass region growing described in Section 7, i.e. the use of algorithms that grow regions so that the difference between the maximum gray level reading and the minimum gray level reading in a region is less than a predefined threshold. The second alternative uses the same region growing where the edge value is taken to be $\left|\sum_{i=1}^{n}\left(X_{2}-Y_{1}\right)\right|$, where $X_{1}$ are the readings from one neighborhood and $Y_{1}$ are those from the other. The neighborhoods are identical to those of the proposed edge operator. In the best case the two alternatives performed similarly to the proposed region grower. However, the threshold settıng had to be adjusted manually between pictures until the performance became comparable to the proposed (adaptive) edge detector.

\section{REFERENCES}

1. BaJcY, R. Computer identfication of textured scene. AIM-180, STAN-CS-72-321, Stanford U,, Stanford, Calif., 1972.

2 Barrow, $\mathrm{H}$, AND Popplestone, R Relational description in picture processing Machine Intelligence 6 , B Meltzer and D Michie, Eds, Edınburgh U Press, Edınburgh, 1971, pp 377-396.

3 Berthold, K, AND Horn, P The Binford-Horn Line-Finder Memo No 285, M I T Artificial Intellgence Lab , M I.T , Cambridge, Mass, Dec 1973

4. Binford, T., AND Hershkovitz, A. On boundary detection Memo No 183, M I T Artificial Intelligence Lab., M I T , Cambridge, Mass, Dec 1970.

5. Brice, C , and Fennema, C Scene Analysis Using Regions. J. of Art Intell I (1970), 205-226.

6 Carton, E.J, Et al Some basic edge detection techniques TR-277, Computer Science Center, U. of Maryland, College Park, Md, Dec 1973

7 Davis, L A survey of edge detection techniques C S TR-273, U of Maryland, College Park, Md, 1973

8 Fukunaga, K. Introduction to Statistical Pattern Recognition Academic Press, New York, 1972.

9 GRIFFTtr, A Mathematical models for automatic line detection.J ACM 20, 1 (Jan. 1973), 62-80

10. Griffrth, A Edge detection in simple scenes using a prion information IEEE Trans. on Computers C-22 (April 1973), 371-381

11. Harlow, C A., AND EISEnBeis, S.A. The analysis of radıographic images. IEEE Trans on Computers C-22 (1973), 678-689

12 Horowitz, S, and Pavlidis, T Picture segmentation by a direct split and merge method Proc 2nd Jount Int Conf of Pattern Recognition, IEEE Pub 74CHO-885-4C, Aug 1974, pp. 424-433

13 Hueckel, M H. A local visual operator which recognizes edges and hnes J. ACM 20, 4 (Oct 1973), 634-647

14. Lipkin, B , And Rosenfeld, A Picture Processing and Psychopictorics Academic Press, New York, 1970, pp 382-383.

15. Martelur, A Edge detection using heuristic search method. Computer Graphics and Image Processing (1972), 169-182

16 Nitsson, N. Problem Solving Methods in Arttfictal Intelligence. McGraw-Hill, New York, 1971

17 Pingle, $K$, and Tenenbaum, J An accommodating edge follower. Proc International Joint Conf on Artıficial Intelligence, Britısh Computer Soc, London, England, Sept 1971, pp 1-7

18 Rosenfeld, A Picture processing by computer Computing Surveys 1,3 (Sept 1969), 147-176.

19 Rosenfeld, A Progress in picture processing 1969-1971 C S TR-176, U of Maryland, College Park, Md, Jan 1972

20 Rosenfeld, A Picture processing: 1972 C S TR-217, U. of Maryland, College Park, Md, Jan. 1973

21. ShIraI, Y A step toward context-sensitive recognition of Irregular objects. Computer Graphics and Image Processing 2, 3 (Dec 1973), 298-307

22 Tenenbaum, J Accommodation in computer vision EE Th, Stanford U, Stanford, Calif, 1970

23. Tomita, F, ET AL Detection of homogeneous regions by structural analysis Proc 3rd Int Joint Conf on Artifıcial Intelligence, Aug 1973, pp 364-371

24 YAKIMOVSKY, Y Scene analysis using a semantic base for region growing STAN-CS-73-380, Stanford U, Stanford, Calıf., June 1973

25 Yakimovsky, Y. On the recognition of complex structures Proc. of 2nd Joint Int Conf of Pattern Recognition, IEEE Pub 74CHO-885-4C, Aug. 1974, pp 345-353

RECEIVED JUNE 1974, REVISED MARCH 1976 